\title{
REVIEW
}

\section{Prevalence of Primary Aldosteronism: Should We Screen for Primary Aldosteronism before Treating Hypertensive Patients with Medication?}

\author{
TETSUO NISHIKAWA, JUn SAITO AND MASAO OMURA* \\ Division of Endocrinology \& Metabolism, Department of Medicine, Yokohama Rosai Hospital, Yokohama City, Kanagawa 222-0036, \\ Japan \\ *Department of Medical Examination, Yokohama Rosai Hospital, Yokohama City, Kanagawa 222-0036, Japan
}

\begin{abstract}
The present review examines various reports describing prevalence of primary aldosteronism (PA) among hypertensives and the screening method of PA to better understand the current concepts used for diagnosing and managing PA among clinicians as well as specialists. Here, we describe and compare the prevalence of PA in Japan, which is well known to induce various vascular complications due to hyperaldosteronemia, resulting in cerebral infarction, myocardial infarction and renal failure, with that in another Asian area, US, European countries, Australia and Africa. The incidence rates for PA among hypertensives were recently reported to be widely raged between $3.2 \%$ and $20 \%$. Those discrepancies are due in part to the completely different characteristics of the starting subjects used for studying the prevalence. Moreover, the criteria for screening PA among hypertensives, including aldosterone-renin ratio (ARR), and confirmatory tests for definitely diagnosing PA, such as saline infusion test are varied. We had already reported that a diagnosis of PA was made in $61(6 \%)$ of the 1,020 hypertensive patients during the past five years, from 1995 until 1999. In our study, only $18 \%$ of the patients showed a serum $\mathrm{K}$ level of $3.3 \mathrm{mEq} / \mathrm{l}$ or less. Thus, many clinicians seem to misdiagnose PA as essential hypertension, because of absence of hypokalemia. Finally, we describe highlight key evidence for optimal methods for screening and definitely diagnosing PA among hypertensive patients in order to avoid misjudgment before or after treating hypertensive patients.
\end{abstract}

Key words: Plasma renin activity, Plasma aldosterone concentration, Aldosterone-renin ratio (ARR), Hypertension, Adrenal adenoma, Adrenal hyperplasia

(Endocrine Journal 54: 487-495, 2007)

\section{Primary aldosteronism is a common disease}

It is intriguing to consider the possibility that there might be a clearly defined cause for hypertension. Padfield had already reported that cardiovascular risk factors, which can affect as much as $50 \%$ of an older population, would be transformed if there were a specific cause or causes amenable to specific therapies [1]. There are now increasing numbers of critical reports suggesting that the prevalence of primary aldosteronism (PA) might be approximately $10 \%$ of all of those individuals with hypertension. This would

Correspondence to: Tetsuo NISHIKAWA, M.D., Ph.D., Department of Medicine, Yokohama Rosai Hospital, 3211 Kozukue-cho, Kohoku-ku, Yokohama City 222-0036, Japan make PA more common than diabetes or thyroid disease and would surely revolutionize our approach to the management of those thousands of patients with what has previously been called essential hypertension [1].

Nearly decade after Conn described the syndrome of PA in 1955 [2], he and his co-workers suggested that hypertension due to PA may exist for many years before hypokalemia becomes demonstrable [3]. The availability of assays for plasma renin activity (PRA) made it possible to study groups of patients with essential hypertension with respect to both PRA and aldosterone secretion rates [3]. Conn suggested using the unique combination of decreased or absent PRA together with an increased secretion of aldosterone rather than hypokalemia as the initial indicator of PA. 
Loh et al. [4] described that Conn [5] proved the existence of normokalemic PA with his report of 14 such patients, all of whom underwent successful surgeries with tumor sizes ranging from $2-18 \mathrm{~mm}$ in diameter, despite facing skepticism. Unfortunately, Conn's observation that PA occurred even in normokalemic subjects and his recommendation that every patient with essential hypertension should undergo appropriate testing to exclude this entity were subsequently forgotten by most clinicians [4].

Nadar's review article [6] described that the accepted prevalence worldwide of PA in unselected patients with hypertension is now considered to be low, perhaps about $2 \%$ or even less than $1 \%$ [7], although there are recent reports suggesting higher values of up to $10-15 \%$ of patients with hypertension $[8,9]$. Nevertheless, there have always been wide variations in the reported prevalence of hyperaldosteronism [6]. When Conn first described the syndrome, he estimated that about $20 \%$ of hypertensives would have an adrenal adenoma [10]. This figure included all adrenal tumors, but it is now known that non-functioning nodules, macronodules and adenomas (sometimes known as incidentalomas) become increasingly common with advancing age $[11,12]$.

After the initial description by Conn, studies in Caucasian populations suggested a prevalence of about $6 \%$ [13]. Following this, a review of autopsy studies from Johns Hopkins Hospital [14] revealed a prevalence of true adenomas of $1.97 \%$. In the mid-1970s the widespread use of diuretics in hypertension led many patients with hypertension and hypokalemia, who were until then undiagnosed, to be identified as having adrenal hyperplasia or adrenal adenomas. However, once this 'backlog' was dealt with, the prevalence appeared to decline and many centers published very low prevalence values. The SUNY Health Science Center in Syracuse [15] reported a prevalence ranging from $1.5 \%$ to $2.7 \%$ of their hypertensive patients. It should be noted that, in all these reports, the prevalence or incidence values depend upon the cut-off values for diagnosing PA, as well as on the histological criteria for diagnosis $[6,12]$.

We performed PA screening in 1,020 Japanese patients with hypertension, as described in detail below, and this disorder was detected in $6.0 \%$ of the patients [16]. We checked the basal levels of plasma aldosterone concentration (PAC) and PRA in all hypertensives whose blood was obtained in a recumbent position for at least 30 minutes in the morning. The patients with hyporeninemic hyperaldosteronemia were selected according to our criteria, such as more than $12.0 \mathrm{ng} / \mathrm{dl}$ of PAC and less than $1.0 \mathrm{ng} / \mathrm{mL} / \mathrm{hr}$ of PRA. Then, furosemide plus a two-hour upright test was performed for detecting the unresponsiveness of PRA to this test. The patients showing unresponsiveness of PRA to furosemide plus the upright test were tentatively diagnosed with PA. All cases tentatively diagnosed at the outpatient clinic were admitted to the Department of Endocrinology and Metabolism, Yokohama Rosai Hospital, in order to clarify exactly the diagnosis and imaging of adrenals. The diagnosis of PA was confirmed by a captopril-loading test. The laterality of hyperaldosteronism was determined by $\mathrm{CT}$ and selective adrenal venous sampling. This led to an increase in diagnoses of PA.

The plasma levels of potassium were less than $3.3 \mathrm{mEq} / \mathrm{L}$ only in $18 \%$ of all patients with confirmed PA $[16,17]$. It was reported that of the 90 patients with essential hypertension (EHT), not more than three patients (less than 3.3\%) satisfied the diagnostic criteria for PA [18], and it was also reported that hypokalemia is of great value in suggesting the presence of PA [18]. Komiya et al. had reported that there were 31 patients with PA (20 cases of aldosterone-producing adenoma and 11 patients of idiopathic hyperaldosteronism) among 772 Japanese hypertensives, suggesting that the prevalence of PA is $4.0 \%$ [19]. The prevalence of PA is gradually increasing, although PA was thought to be a very rare cause of hypertension. It has been reported that diagnoses of PA increased from fewer than ten cases per year to 90 per year in the Hypertension Unit at Greenslopes Hospital, Brisbane, Australia, since the aldosterone-renin ratio (ARR) for identifying patients with PA, combined with the fludrocortisone suppression test, has been applied to all hypertensives [20]. Most of their patients with PA come from screening normokalemic hypertensives [20], suggesting that the incidence of PA rises after screening previously untested normokalemic hypertensives.

On the other hand, Gordon described that the incidence of PA among hypertensives is unknown, and may vary with geography and ethnicity [20]. The recent incidence of PA has been reported to be almost $20 \%$ among patients with EHT, from the data of the Mayo Clinic [21]. They screen PA by an ARR of more than $15 \mathrm{ng} / \mathrm{dl}$ of PAC, and the annual incidence of PA 
now shows a tenfold increase during these eight years, compared with that before 1990 [21].

The results obtained from these prevalence studies may be biased because hypertensive subjects were recruited from specialist referral centers. Nevertheless, in the only study conducted in a primary care practice, Lim and colleagues in the United Kingdom [22] found elevated ARR in $14.4 \%$ of their patients, similar to the proportion obtained from their earlier study in specialist referral clinics. They concluded that about 1 in 10 of their hypertensive patients had PA, however, these figures were based only on the projected positive predictive value of their ARR cut-off, as confirmatory tests were not performed in these subjects.

The prevalence of PA, as reported from 1994 to 2006, is summarized in Table 1 . The incidence rates ranged widely between $3.2 \%$ and $21.7 \%$. As shown in Table 1, subjects for the study analysis were quite dif- ferent, such as unselected hypertensives or patients referred to the hypertension unit. Such discrepancies are not unusual, because the characteristics of starting subjects for studying the prevalence were completely different. Moreover, the criteria for screening PA among hypertensives, including the value of ARR, and confirmatory tests for definitely diagnosing PA, such as the saline infusion test, are varied, according to each report (Table 1). Thus it is not always possible to compare the prevalence rate of PA in our experiments $[16,17]$ with the others described in Table 1 . As shown in Table 1, our data reported in 2000 [17] are not completely consistent with those in 2004 [16]. We have already reported the incidence of PA in these 1,020 patients in our previous report [17]; however, we diagnosed 6 more patients with PA in this population [16] after submitting the previous report [17]. Those data shown in Table 1 demonstrated that PA is not rare

Table 1. Prevalence of primary aldosteronism

\begin{tabular}{|c|c|c|c|c|}
\hline Authors (year) & Subjects & Screening test & $\begin{array}{l}\text { Confirmatory test for } \\
\text { diagnostic examination }\end{array}$ & $\begin{array}{c}\text { Prevalence of } \\
\text { PA }\end{array}$ \\
\hline Gordon et al. (1994) [8] & $\begin{array}{l}199 \text { hypertensive patients } \\
\text { referred to hypertension unit }\end{array}$ & $\begin{array}{l}\mathrm{ARR}>30 \text { seated for } 5 \mathrm{~min} \\
\text { medication was continued }\end{array}$ & FST & $8.5 \%$ \\
\hline Komiya et al. (1996) [19] & 741 hypertensive patients & & & $4.2 \%$ \\
\hline Lim et al. (2000) [9] & $\begin{array}{l}495 \text { hypertensive patients } \\
\text { referred to hypertension unit }\end{array}$ & $\begin{array}{l}\text { ARR }>27 \text { sitting for } 10 \mathrm{~min} \\
\text { medication was stopped }\end{array}$ & FST and salt loading test & $9.2 \%$ \\
\hline Fardella et al. (2000) [23] & $\begin{array}{l}305 \text { hypertensive patients } \\
\text { referred to hypertension unit }\end{array}$ & $\begin{array}{l}\mathrm{ARR}>50 \text { and } \mathrm{PAC}>16 \mathrm{ng} / \mathrm{dl} \\
\text { sitting for } 15 \mathrm{~min}\end{array}$ & FST & $9.5 \%$ \\
\hline Loh et al. (2000) [4] & 350 hypertensive patients & $\begin{array}{l}\mathrm{ARR}>20 \text { and } \mathrm{PAC}>15 \mathrm{ng} / \mathrm{dl} \\
\text { seated for } 15 \mathrm{~min} \\
\text { medication was continued }\end{array}$ & Salt loading test & $4.6 \%$ \\
\hline Rossi et al. (2002) [24] & $\begin{array}{l}1065 \text { hypertensive patients } \\
\text { referred to hypertension unit }\end{array}$ & $\begin{array}{l}\text { postcaptopril } \mathrm{ARR}>35 \\
\text { seated for } 90 \mathrm{~min}\end{array}$ & Saline loading test & $6.3 \%$ \\
\hline Strauch et al. (2003) [25] & $\begin{array}{l}402 \text { moderate to severe } \\
\text { hypertensives referred to } \\
\text { hypertension unit }\end{array}$ & $\mathrm{ARR}>50$ & & $19 \%$ \\
\hline \multicolumn{5}{|l|}{ Mulatero et al. (2004) [26] } \\
\hline Mulatero et al. & $\begin{array}{l}7343 \text { hypertensive patients } \\
\text { referred to hypertension unit }\end{array}$ & $\mathrm{ARR}>40$ and $\mathrm{PAC}>15 \mathrm{ng} / \mathrm{dl}$ & Saline loading test & $8 \%$ \\
\hline Young et al. & 1112 hypertensives & $\mathrm{ARR}>20$ and $\mathrm{PAC}>15 \mathrm{ng} / \mathrm{dl}$ & Salt loading test & $10.8 \%$ \\
\hline Stowesser et al. & & $\mathrm{ARR}>30$ & FST & $21.7 \%$ \\
\hline Loh et al. & 3850 patients & $\mathrm{ARR}>20$ & Saline loading test & $4.6 \%$ \\
\hline $\begin{array}{l}\text { Nishikawa \& Omura (2000) [17] } \\
\text { Omura et al. (2004) [16] }\end{array}$ & $\begin{array}{l}1020 \text { hypertensives visiting } \\
\text { general outpatient clinic }\end{array}$ & $\begin{array}{l}\mathrm{PAC}>12 \mathrm{ng} / \mathrm{dl} \text { and } \\
\mathrm{PRA}<1.0 \mathrm{ng} / \mathrm{ml} / \mathrm{h} \text { rested in } \\
\text { spine position for } 30 \mathrm{~min} \\
\text { without medication }\end{array}$ & ACTH-AVS & $5.4 \%-6.0 \%$ \\
\hline Williams et al. (2006) [27] & $\begin{array}{l}346 \text { mild to moderate } \\
\text { hypertension }\end{array}$ & $\mathrm{ARR}>25$ and $\mathrm{PAC}>8 \mathrm{ng} / \mathrm{dl}$ & Urinary aldosterone excretion & $3.2 \%$ \\
\hline
\end{tabular}

Summarized data by Mulatero et al. [26] gives results which were collected from various countries. ARR: aldosterone-renin ratio; PRA: plasma rennin activity; PAC: plasma aldosterone concentration; FST: fludrocortisone-suppression test. 
among hypertensives. We should take note that many clinicians seem to misdiagnose PA as essential hypertension, because of the absence of hypokalemia. We therefore need to determine the PRA and PAC before treating hypertensives, although those hormonal examinations were reported to be economically impractical [28]. Vascular complications, including cerebral infarction and myocardial infarction, are frequently observed in patients with PA [29-32]. Thus, we should make an appropriate early diagnosis of PA in hypertensives and also even in normotensives in order to prevent various aldosterone-induced vasculopathies, because there has been a report demonstrating a case of normotensive PA [33].

In addition, racial differences must be considered. Gordon et al. [8] reported a $12 \%$ probable incidence of PA among 199 selected normokalemic hypertensive patients in Australia. As not all subjects who screened positive underwent confirmatory studies, the minimum incidence based on biochemically confirmed cases from this selected Caucasian hypertensive population was $8.5 \%$. The reported prevalence of PA obtained from the small number of studies performed in other selected Caucasian hypertensive populations ranged from $2.7-16.6 \%[34,35]$; whereas, an Asian study reported an $8.7 \%$ prevalence of PA and a $2.9 \%$ incidence of unilateral adrenal adenomas [36]. A study from Singapore [4] suggested that the prevalence of primary hyperaldosteronism was higher in the Chinese population (about $5-15 \%$ ), with most of the patients having normal serum potassium. Another study, from South Africa [37], suggested a prevalence range of 3.3$10.1 \%$ of all their patients with hypertension. This study is particularly interesting as it was found that, although normotensive blacks had significantly lower plasma renin activity and aldosterone than their white counterparts, there was no significant difference between the ethnic groups among the hypertensive patients, suggesting that the different prevalence rates have geographic rather than racial causes. In a review involving 7 areas between 1981 and 2003, the incidence of PA was $6.6 \%$ [38], which was similar to what we reported $(6 \%)[16,17]$; internationally, the incidence of PA in hypertension patients was estimated to be $6 \%$.

\section{How to screen PA}

The incidence of PA differs among screening methods. The apparent increase in the reported prevalence of PA over the last decade is likely to reflect the improvement in screening methodologies. Using the ARR as a screening tool, Hiramatsu and colleagues [39] identified and successfully operated on 9 patients with aldosterone-producing adenoma from a study of 348 hypertensive patients, thus giving a prevalence of $2.6 \%$ for aldosterone-producing adenoma in a hypertensive population from Japan. Importantly, they were able to demonstrate that the finding of normokalemia provided little assurance that aldosterone-producing adenoma was absent, as normokalemia was found in 6 of the 9 patients. It was reported that no patient showed a falsely elevated ARR [40]. Data suggest that the ARR is a valid screening assay for PA in patients with poorly controlled blood pressure, and discontinuation of antihypertensive medications is not needed for this test [40].

In our method, patients with hypertension were rested in bed for 30 minutes, and blood was collected to measure the PRA and the PAC $[16,17]$. Screening was performed in patients with a PRA value of less than $1.0 \mathrm{ng} / \mathrm{ml} / \mathrm{hr}$ and a PAC of $12.0 \mathrm{ng} / \mathrm{dl}$ or more. We conducted a furosemide load test with patients in the upright position for 2 hours. In patients in whom PRA was less than $1.0 \mathrm{ng} / \mathrm{ml} / \mathrm{hr}$ after 2 hours, further investigation was performed under a tentative diagnosis of PA. In addition, we conducted a captopril $(50 \mathrm{mg})$ load test, and patients with a ARR value of more than 25 after 90 minutes were diagnosed as having PA via autonomous aldosterone secretion [16]. Of the 1,020 patients with hypertension, 119 met the criteria: a PRA value of less than $1.0 \mathrm{ng} / \mathrm{ml} / \mathrm{hr}$ and a PAC of $12.0 \mathrm{ng} / \mathrm{dl}$ or more. In 83 patients, PRA was less than $1.0 \mathrm{ng} / \mathrm{ml} / \mathrm{hr}$ after the furosemide loading plus 2-hour upright test. After admission, the results of further examinations, including ACTH-stimulated adrenal venous sampling, suggested a definite diagnosis of PA in 61 patients [16]. We performed the screening test based on absolute values of PRA and PAC. However, many studies have employed the ARR as a simple and useful index of PA. Hiramatsu et al. [39] initially used this index for PA screening; antihypertensive agents were discontinued in the presence of a standard diet, and blood was collected in the standing position to compare ARR. This procedure 
facilitates PA screening, with a cut-off value of 40 . Their study included patients who were referred for detailed examination of hypertension, but not any outpatients. Therefore, a prospective survey involving residents and primary-care patients should be performed to compare the cut-off value. In addition, to establish specific diagnostic criteria, conditions such as posture at blood collection (standing, supine, and sitting positions), diet (free, salt restricted), and antihypertensive agents (after treatment for a few weeks, no administration, and low-dose therapy permitted) must be standardized. Estimation of the ARR value is not always done as a routine procedure on all patients with hypertension, since PRA as low as $0.1 \mathrm{ng} / \mathrm{mL} / \mathrm{h}$, which is often reported in elderly people, black people, and people with hypertension [41], would give a raised ARR even if the PAC is low or normal [42]. As reported by Fardella et al. [23], absolute values of ARR and PAC should be considered in addition to cut-off values for accurate screening. Therefore, we reported that a PRA value of $1 \mathrm{ng} / \mathrm{ml} / \mathrm{hr}$ or less with a PAC of $12 \mathrm{ng} / \mathrm{dl}$ or more suggested PA, and did not perform screening with ARR. To investigate the reproducibility of PRA, PAC and ARR, Tanabe et al. [43] compared these parameters after collecting several blood samples in 71 patients with PA. In all patients, blood samples were collected without restricting their diet (salt intake), medication, posture or the timing of blood collection. The PRA and PAC values were normal in some patients, and they indicated that it was difficult to evaluate the presence or absence of PA using a single blood sample; PA should be diagnosed using several blood samples. Furthermore, they compared PAC between blood samples collected at the outpatient clinic and those from the ward of the in-patient clinic, and finally demonstrated that the former samples showed a significantly lower value. Therefore, specific conditions for blood collection should be established. A systematic review of the prospective reports of the ARR as a screening test for PA in patients with presumed essential hypertension [44]. The authors [44] mentioned that it remains a nonstandardized test of the ARR since investigators have not systematically studied the impact of alternative testing conditions, such as position, diet and anti-hypertensive medication use at the time for determining the ARR. Thus, we always examined patients with hypertension, who were rested in bed for 30 minutes in the morning, and blood was collected to measure PRA and PAC. Screening was performed in patients with a PRA value of less than $1.0 \mathrm{ng} / \mathrm{ml} / \mathrm{hr}$ and a PAC of $12.0 \mathrm{ng} / \mathrm{dl}$ or more. We need further studies for determining the cut-off value of the ARR to screen probable cases with PA among unselected hypertensives.

Concerning the significance of the serum potassium (K) level in the diagnosis of PA, Gordon suggested that PA screening with the serum $\mathrm{K}$ level is difficult, as all PA patients initially develop normokalemia (normokalemic PA and hypokalemic PA are not different entities) [20]. The serum $\mathrm{K}$ level may be influenced by dietary factors, such as salt intake, the severity of PA and the period of excessive aldosterone secretion. In addition, this parameter may depend on the aldosterone sensitivity of the renal tubules in individual patients with PA. Therefore, they indicated that $\mathrm{PA}$ is exactly present regardless of the serum $\mathrm{K}$ level (normokalemia or hypokalemia). In our study, only $18 \%$ of the patients showed a serum $\mathrm{K}$ level of $3.3 \mathrm{mEq} / \mathrm{l}$ or less $[16,17]$. If our patients had been screened based on the serum $\mathrm{K}$ level alone, $82 \%$ of them would have been missed.

\section{Classification of subtypes of PA}

PA is endocrinologically and pathophysiologically classified as a form of aldosterone-producing adenoma (APA) [2], idiopathic hyperaldosteronism (IHA) [45], unilateral adrenal hyperplasia (UAH) [46], primary adrenal hyperplasia [47], adrenal cancer [48], glucocorticoid remediable aldosteronism [49], familial hyperaldosteronism type II [50] and unilateral multiple adrenocortical micronodules (UMN) [51]. The most common types of PA are APA and IHA. APA typically responds to unilateral adrenalectomy, which corrects hyperaldosteronemia and can attenuate hypertension. The medical management of IHA is generally recommended [52-55], since unilateral or subtotal adrenalectomy results in the rates of cure of hypertension only $15-20 \%$ [47, 52]. Therefore, distinguishing APA from IHA is critical for deciding on the type of treatment.

It has been reported that among the PA types, solitary adrenal adenoma-related PA (APA) comprises the highest proportion (more than 50\%) [56]. Idiopathic hyperaldosteronism (IHA) with micronodular or nodular hyperplasia of the bilateral adrenal glands comprises 20 to $30 \%$ of PA patients [57]. Gordon [20] 
reported that IHA comprised 70 to $80 \%$ of PA patients. Young [21] indicated that IHA comprised approximately $80 \%$.

There is a limitation for differentiating APA from IHA, because the size of APA is usually so small that CT images cannot always detect the lesions [16, 17, $51,58]$. In evaluating whether the lesion involves the unilateral or bilateral adrenal glands, diagnostic imaging of the adrenal glands is less accurate, and microlesions may frequently be missed, resulting in a diagnosis of IHA. We compared the proportion of each disease type classified based on the etiologies of PA, with our data (Fig. 1) [59]. We collected adrenal venous blood under ACTH loading in all patients to make a definitive diagnosis of hyperaldosteronism and to detect the laterality of the adrenal lesion. In addition, we differentiated between unilateral and bilateral adrenal lesions in PA by histopathological examinations of the resected adrenal tissues $[16,17,51,58]$. In our data [16], adenoma patients comprised $74 \%$, and the proportion of patients with IHA in PA patients was markedly lower than the values in other studies, except the previous findings reported by Phillips et al. [60] (Table 2). In the diagnosis of PA, localization should be accurately evaluated in order to select appropriate therapeutic strategies, such as unilateral adrenalectomy and drug treatment.

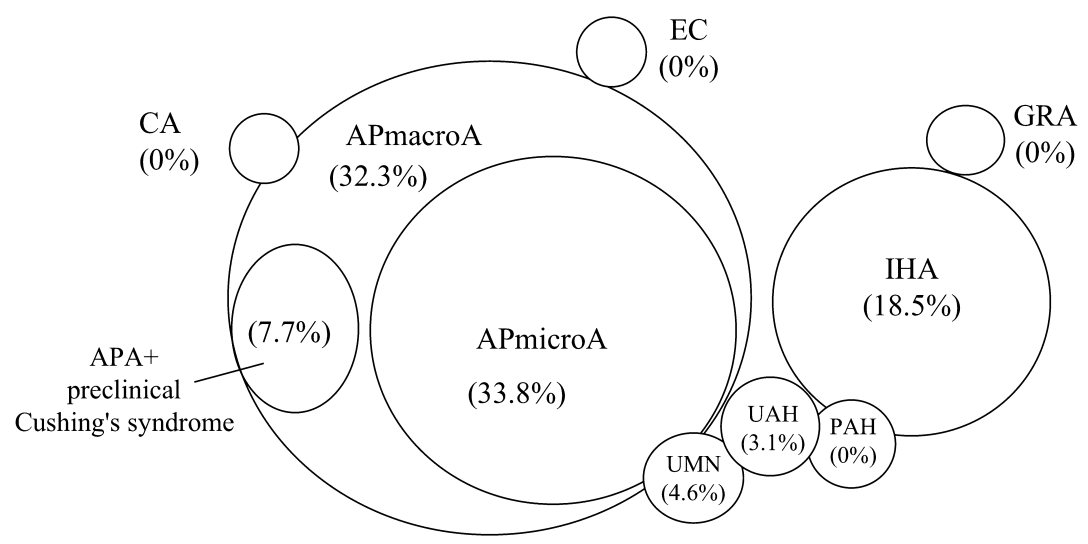

Fig. 1. Incidences of each subtype of PA among 65 cases of PA. APmicroA: aldosterone-producing microadenoma, APmacroA: aldosterone-producing macroadenoma, APA: aldosterone-producing adenoma, IHA: idiopathic hyperaldosteronism, GRH: glucocorticoid-remediable hyperaldosteronism, UAH: unilateral adrenal hyperplasia, PAH: primary adrenal hyperplasia, UMN: unilateral multiple adrenocortical micronodules, EC: ectopic aldosteronism, CA: carcinoma

Table 2. Proportion of aldosterone-producing adenoma (APA) and idiopathic hyperaldosteronism (IHA) among PA patients

\begin{tabular}{llcc}
\hline \multicolumn{1}{c}{ Authors (year) } & $\begin{array}{c}\text { Method of } \\
\text { differential diagnosis }\end{array}$ & APA & IHA \\
\hline Phillips et al. (2000) [60] & ACTH-AVS & $85 \%$ & $15 \%$ \\
Omura et al. (2004) [16] & ACTH-AVS & $74 \%$ & $20 \%$ \\
Young et al. (2004) [61] & ACTH-AVS & $53 \%$ & $43 \%$ \\
Loh et al. (2000) [4] & AVS & $50 \%$ & $50 \%$ \\
Rossi et al. (2001) [62] & AVS & $39 \%$ & $61 \%$ \\
Strauch et al. $(2003)[25]$ & AVS & $36 \%$ & $42 \%$ \\
Stowasser et al. (2003) [63] & AVS & $31 \%$ & $69 \%$ \\
Young (2003) [64] & AVS & $28 \%$ & $72 \%$ \\
Lim et al. (2000) [9] & CT & $12 \%$ & $78 \%$ \\
Fardella et al. (2000) [23] & CT & $4 \%$ & $96 \%$ \\
\hline
\end{tabular}

Note: ACTH-AVS: ACTH-stimulated adrenal venous sampling; AVS: adrenal venous sampling; CT: computed tomography. 


\section{Conclusion}

The present review revealed that the incidence of PA is unexpectedly high among patients with hypertension, and that aldosterone-producing adenoma, which seems to be a main cause of PA, can be simply treated by unilateral adrenalectomy, although Kaplan [65] had recently reported that expensive laboratory procedures, invasive diagnostic tests, and unnecessary surgery will be avoided. Thus, it is important to accu- rately diagnose PA and also to differentiate unilateral hyperaldosteronemia from bilateral lesions. Our data suggest that the hyperproduction of aldosterone is only detectable by ACTH-stimulated adrenal venous sampling. Finally, we would like to emphasize that early diagnosis of PA among hypertensive patients by measuring PRA and PAC is essential and important for all clinicians in order to prevent hypertensive vascular complications induced by hyperaldosteronemia.

\section{References}

1. Padfield PL (2003) Prevalence and role of a raised aldosterone to renin ratio in the diagnosis of primary aldosteronism: a debate on the scientific logic of the use of the ratio in practice. Clin Endocrinol 59: 422426.

2. Conn JW (1955) Primary aldosteronism, a new clinical syndrome. J Lab Clin Med 45: 6-17.

3. Conn JW, Cohen EL, Rovner DR (1964) Suppression of plasma renin activity in primary aldosteronism. $J \mathrm{Am}$ Med Assoc 190: 213-221.

4. Loh KC, Koay ES, Khaw MC, Emmanuel SC, Young WF Jr (2000) Prevalence of primary hyperaldosteronism among Asian hypertensive patients in Singapore. J Clin Endocrinol Metab 85: 2854-2859.

5. Conn JW (1968) The evolution of primary aldosteronism: 1954-1967. Harvey Lect 62: 257-291.

6. Nadar S, Lip GYH, Beevers DG (2003) Primary hyperaldosteronism. Ann Clin Biochem 40: 439-452.

7. Connell JM (2002) Is there an epidemic of primary hyperaldosteronism. J Hum Hypertens 16: 151-152.

8. Gordon RD, Stowasser M, Tunny TJ, Klemm SA, Rutherford JC (1994) High incidence of primary hyperaldosteronism in 199 patients referred with hypertension. Clin Exp Pharmacol Physiol 21: 315-318.

9. Lim PO, Dow E, Brennan G, Jung RT, MacDonald TM (2000) High prevalence of primary hyperaldosteronism in the Tayside hypertension clinic population. J Hum Hypertens 14: 311-315.

10. Sherwin RP, Conn JW (1964) Present status of pathology of adrenal gland in hypertension. Am J Surg 107: 136-143.

11. Terzolo M, Ali A, Osella G, Mazza E (1997) Prevalence of adrenal carcinoma among incidentally discovered adrenal masses. A retrospective study from 1989 to 1994. Gruppo Piemontese Incidentalomi Surrenalici. Arch Surg 132: 914-919.

12. Ferriss JB, Beevers DG, Brown JJ, Davies DL, Fraser R, Lever AF, Mason P, Neville AM, Robertson JI (1978) Clinical, biochemical and pathological features of low-renin ('primary') hyperaldosteronism. Am Heart J 95: 375-388.

13. Salomon MI, Tchertkoff V (1968) Incidence and role of adrenocortical tumors in hypertension. Geriatrics 23: 184.

14. Russell RP, Masi AT, Ritcher ED (1972) Adrenal cortical adenomas and hypertension. Medicine 51: 211225 .

15. Anderson GH, Blakerman N, Streeten DHP (1994) The effect of age on prevalence of secondary forms of hypertension in 4429 consecutively referred patients. $J$ Hypertens 12: 609-615.

16. Omura M, Saito J, Yamaguchi K, Kakuta Y, Nishikawa $\mathrm{T}$ (2004) Prospective study on the prevalence of secondary hypertension among hypertensive patients visiting a general outpatient clinic in Japan. Hypertens Res 27: 193-202.

17. Nishikawa T, Omura M (2000) Clinical characteristics of primary aldosteronism: its prevalence and comparative studies on various causes of primary aldosteronism in Yokohama Rosai Hospital. Biomed Pharmacother 54 (Suppl 1): 83-85.

18. Fishman LM, Kuchel O, Liddle GW, Michelakis AM, Gordon RD, Chick WT (1968) Incidence of primary aldosteronism uncomplicated essential hypertension. JAMA 205: 497-502.

19. Komiya J, Yamada T, Takasu N, Asawa T, Akamine H, Yagi N, Nagasawa Y, Ohtsuka H, Miyahara Y, Sakai H, Sato A, Aizawa T (1997) An abnormal sodium metabolism in Japanese patients with essential hypertension, judged by serum sodium distribution, renal function and the renin-aldosterone system. $J$ Hypertens 15: 65-72.

20. Gordon R (1999) Incidence and workup of primary aldosteronism - Greenslopes Hospital Series. Primary aldosteronism and adrenal incidentaloma — into a new millennium. Couran Cove Resort, South Stradbroke Island Queensland, Australia, 13 September, p. 13 (Abstract). 
21. Young WF Jr (1999) Incidence and workup of primary aldosteronism - Mayo Clinic. Primary aldosteronism and adrenal incidentaloma - into a new millennium. Couran Cove Resort, South Stradbroke Island Queensland, Australia, 13 September, p. 12 (Abstract).

22. Lim PO, Rodgers $\mathrm{P}$, Cardale $\mathrm{K}$, Watson $\mathrm{AD}$, MacDonald TM (1999) Potentially high prevalence of primary aldosteronism in a primary-care population. Lancet 353: 40.

23. Fardella CE, Mosso L, Gomez-Sanchez C, Cortes P, Soto J, Gomez L, Pinto M, Huete A, Oestreicher E, Foradori A, Montero J (2000) Primary hyperaldosteronism in essential hypertensives: Prevalence, biochemical profile, and molecular biology. J Clin Endocrinol Metab 85: 1863-1867.

24. Rossi E, Regolisti G, Negro A, Sani C, Davoli S, Perazzoli F (2002) High prevalence of primary aldosteronism using postocaptopril plasma aldosterone to renin ratio as a screening test among Italian hypertensives. Am J Hypertens 15: 896-902.

25. Strauch B, Zelinka T, Hampf M, Bernhardt R, Widimsky J Jr (2003) Prevalence of primary hyperaldosteronism in moderate to severe hypertension to serve hypertension in the Central Europe region. J Hum Hypertens 17: 349-352.

26. Mulatero P, Stowasser M, Loh KC, Fardella CE, Gordon RD, Mosso L, Gomez-Sanchez CE, Veglio F, Young WF Jr (2004) Increased diagnosis of primary aldosteronism, including surgically correctable forms, in centers from five continents. $J$ Clin Endocinol Metab 89: 1045-1050.

27. Williams JS, Williams GH, Raji A, Jeunemaitre X, Brown NJ, Hopkins PN, Conlin PR (2006) Prevalence of primary hyperaldosteronism in mild to moderate hypertension without hypokalemia. $J$ Hum Hypertens 20: 129-136.

28. Kaplan NM (2004) The current epidemic of primary aldosteronism: causes and consequences. J Hypertens 22: 863-869.

29. Rossi GP, Sacchetto A, Pavan E, Palatini P, Graniero GR, Canali C, Pessina AC (1997) Remodeling of the left ventricular in primary aldosteronism due to Conn's adenoma. Circulation 95: 1471-1478.

30. Schmidt BM, Schmieder RE (2003) Aldosteroneinduced cardiac damage: focus on blood pressure independent effect. Am J Hypertens 16: 80-86.

31. Sato A, Saruta T (2004) Aldosterone-induced organ damage: plasma aldosterone level and inappropriate salt status. Hypertens Res 27: 303-310.

32. Takeda Y (2004) Pleiotropic action of aldosterone and the effects of eplerenone, a selective mineralocorticoid receptor antagonist. Hypertens Res 27: 781-789.

33. Kono $\mathrm{T}$, Ikeda $\mathrm{F}$, Oseko $\mathrm{F}$, Imura $\mathrm{H}$, Tanimura $\mathrm{H}$ (1981) Normotensive primary aldosteronism: report of a case. J Clin Endocrinol Metab 52: 1009-1013.
34. Brown MA, Cramp HA, Zammit VC, Whitworth JA (1996) Primary aldosteronism: a missed diagnosis in "essential hypertensives"? Aust NZ J Med 26: 533-538.

35. Lim PO, Brennan G, Shiels P, et al. (1998) Unexpectedly high prevalence of primary aldosteronism in a hypertensive population in Dundee, Edinburgh (Abstract). British Endocrine Society. J Endocrinol 156 (Suppl):S1-43.

36. Kumar A, Lall SB, Ammini A, Peshin SS, Karmarkar MG, Talwar KK, Sath SD (1994) Screening of a population of young hypertensives for primary hyperaldosteronism (correspondence). J Hum Hypertens 8: 731732.

37. Rayner BL, Opie LH, Davidson JS (2000) The aldosterone/renin ratio as a screening test for primary hyperaldosteronism. S Afr Med J 90: 394-400.

38. Plouin PF, Amar L, Chatellier G on behalf of the COMETE-Conn Study Group (2004) Trends in the prevalence of primary aldosteronism, aldosteroneproducing adenomas, and surgically correctable aldosterone-dependent hypertension. Nephrol Dial Transplant 19: 774-777.

39. Hiramatsu K, Yamada T, Yukimura Y, Komiya I, Ichikawa $K$, Ishihara $M$, Nagata $H$, Izumiyama $T$ (1981) A screening test to identify aldosterone-producing adenoma by measuring plasma renin activity: results in hypertensive patients. Arch Intern Med 141: 1589-1593.

40. Gallay BJ, Ahmad S, Xu L, Toivola B, Davidson RC (2001) Screening for primary aldosteronism without discontinuing hypertensive medications: plasma aldosterone-renin ratio. Am J Kidney Dis 37: 699-705.

41. Kaplan NM (1998) Primary hypertension: pathogenesis. Clinical Hypertension, 7th edn. Baltimore: Williams and Wilkins, 60-63.

42. Kaplan NM (2001) Cautions over the current epidemic of primary aldosteronism. Lancet 357: 953-954.

43. Tanabe A, Naruse M, Takagi S, Tsuchiya K, Imaki T, Takano K (2003) Variability in the renin-aldosterone profile under random and standardized sampling conditions in primary aldosteronism. J Clin Endocrinol Metab 88: 2489-2494.

44. Montori VM, Young WF Jr (2002) Use of plasma aldosterone concentration-to-plasma renin activity ratio as a screening test for primary aldosteronism. A systematic review of the literature. Endocrinol Metab Clin N Am 31: 619-632.

45. Van Buchem FSP, Doorenbos H, Elings HS (1956) Primary aldosteronism due to adrenocortical hyperplasia. Lancet 271: 335-337.

46. Ross EJ (1965) Conn's syndrome due to adrenal hyperplasia with hypertrophy of zona glomerulosa, relieved by unilateral adrenalectomy. Am J Med 39: 994-1002.

47. Banks WA, Kastin AJ, Biglieri EG, Ruiz AE (1984) Primary adrenal hyperplasia: A new subset of primary 
hyperaldosteronism. J Clin Endocrinol Metab 58: 783785.

48. Foye LV Jr, Feichtmeir TV (1955) Adrenal cortical carcinoma producing solely mineralocorticoid effect. Am J Med 19: 966-975.

49. Sutherland DJA, Ruse JL, Laidlaw JC (1966) Hypertension, increased aldosterone secretion and low plasma renin activity relieved by dexamethasone. Canad Med Ass J 95: 1109-1119.

50. Gordon RD, Stowasser M, Tunny TJ, Klemm SA, Finn WL, Krek AL (1991) Clinical and pathological diversity of primary aldosteronism including a new familiar variety. Clin Exp Pharmacol Physiol 18: 283-286.

51. Omura M, Sasano H, Fujiwara T, Yamaguchi K, Nishikawa T (2002) Unique cases of unilateral hyperaldosteronism due to multiple adrenocortical micronodules, which can only be detected by selected adrenal venous sampling. Metabolism 51: 350-355.

52. Weinberger MH, Grim CE, Hollifield JW, Kem DC, Ganguly A, Kramer NJ, Yune HY, Wellman H, Donohue JP (1979) Primary aldosteronism. Ann Intern Med 90: 386-395.

53. Ganguly A (1998) Primary aldosteronism. New Engl J Med 339: 1828-1834.

54. Stewart PM (1999) Mineralocorticoid hypertension. Lancet 353: 1341-1347.

55. Lim PO, Young WF, MacDonald TM (2001) A review of the medical treatment of primary aldosteronism. $J$ Hypertens 19: 353-361.

56. Blumenfeld JD, Sealey JE, Schlussel Y, Vaughan ED Jr, Sos TA, Atlas SA, Muller FB, Acevedo R, Ulick S, Laragh JH (1994) Diagnosis and treatment of primary hyperaldosteronism. Ann Intern Med 121: 877-885.

57. Weinberger MH, Grim CE, Hollifield JW (1979) Primary hyperaldosteronism. Diagnosis, localization and treatment. Ann Intern Med 67: 403-413.

58. Omura M, Sasano H, Saito J, Yamaguchi K, Kakuta Y, Nishikawa T (2006) Clinical characteristics of aldo- sterone-producing microadenoma, macroadenoma, and idiopathic hyperaldosteronism in 93 patients with primary aldosteronism. Hypertens Res 29: 883-889.

59. Nishikawa T, Saito J, Omura M (2006) Prospective study on prevalence of aldosterone-producing adenoma and idiopathic hyperaldosteronism among patients with primary aldosteronism. J Tokyo Wom Med Univ 76: 267-269.

60. Phillips JL, Walther MM, Pezzullo JC, Rayford W, Choyke PL, Berman AA, Linehan WM, Doppman JL, Gill JR Jr (2000) Predictive value of preoperative tests in discriminating bilateral adrenal hyperplasia from an aldosterone-producing adrenal adenoma. J Clin Endocrinol Metab 85: 4526-4533.

61. Young WF, Stanson AW, Thompson GB, Grant CS, Farley DR, van Heerden JA (2004) Role of adrenal venous sampling in primary aldosteronism. Surgery 136: 1227-1235.

62. Rossi GP, Sacchetto A, Chiesura-Corona M, De Toni R, Gallina M, Feltrin GP, Pessina AC (2001) Identification of the etiology of primary aldosteronism with adrenal vein sampling in patients with equivocal computed tomography and magnetic resonance findings: results in 104 consecutive cases. J Clin Endocrinol Metab 86: 1083-1090.

63. Stowasser M, Gordon RD, Gunasekera TG, Cowley DC, Ward G, Archibald C, Smithers BM (2003) High rate of detection of primary aldosteronism, including surgically treatable forms, after 'non-selective' screening of hypertensive patients. J Hypertens 21: 2149 2157.

64. Young WF Jr (2003) Minireview: Primary aldosteronism - changing concepts in diagnosis and treatment. Endocrinology 144: 2208-2213.

65. Kaplan NM (2006) Primary aldosteronism, in Kaplan's Clinical Hypertension, Ninth Edition, Lippincott Williams \& Wilkins, p.410-433. 